\title{
Energy-effective Grinding of Inorganic Solids Using Organic Additives
}

\author{
Ratan K. Mishra ${ }^{a}$, Martin Weibel ${ }^{b}$, Thomas Müllerc, Hendrik Heinz ${ }^{\mathrm{d}}$, and Robert J. Flatta
}

Sandmeyer Award 2016

\begin{abstract}
We present our research findings related to new formulations of the organic additives (grinding aids) needed for the efficient grinding of inorganic solids. Even though the size reduction phenomena of the inorganic solid particles in a ball mill is purely a physical process, the addition of grinding aids in milling media introduces a complex physicochemical process. In addition to further gain in productivity, the organic additive helps to reduce the energy needed for grinding, which in the case of cement clinker has major environmental implications worldwide. This is primarily due to the tremendous amounts of cement produced and almost $30 \%$ of the associated electrical energy is consumed for grinding. In this paper, we examine the question of how to optimize these grinding aids linking molecular insight into their working mechanisms, and also how to design chemical additives of improved performance for industrial comminution.
\end{abstract}

Keywords: Agglomeration energy · Ball mill · Clinker · Comminution · Grinding aids · Molecular dynamics · Polycarboxylate ether (PCE) $\cdot$ Sieve residue

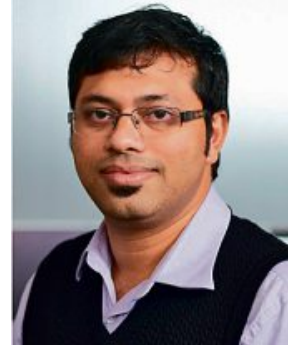

Ratan K. Mishra obtained his PhD in Polymer Engineering, University of Akron, USA, funded by Sika AG, working on the development and applications of interface force fields for construction minerals and inorganic-organic hybrid structures. In his postdoctoral research at ETH Zurich, he completed a collaborative project on multi-scale modeling of chemical admixtures to increase the energy efficiency of clinker grinding. In another project with
LafargeHolcim, he used modeling to uncover the role of setting modifiers in cement. Currently he is a member (senior researcher) of the Swiss Competence Center for Energy Research - Supply of Electricity on 'impact of polymers in cementing of geothermal wells'. He co-leads the design of a force field database of cementitious materials and performance benchmarking at EPFL. His publications include a feature article in Langmuir (2013), first time models of tricalcium silicate and tricalcium aluminate in the Journal of Physical Chemistry $C$ (2013) and in Dalton Transactions (2014), and a review on surface modification of nanostructures in Surface Science Reports (2017). He received the Best Presentation Award at the 13 $3^{\text {th }}$ ICCC, Madrid (2011) and an Outstanding Collaborator Award from Sika Corporate Research, Zurich (2017). and quantum size effects). He obtained his Master degree in Chemistry from the ETH Zürich. Before that, he also attended the art academy (Kunstgewerbeschule ZHdK). Currently he is Senior Project Manager at Sika Technology AG in the CC\&M Shotcrete department. His research topics have been the development of various laboratory test methods, accelerators for sprayed concrete and other admixtures for cementitious materials. Prior to joining Sika, he worked as Senior Scientist at BASF for 16 years. He holds six patents in the area of sprayed concrete. His broad research experience in organic, inorganic, polymer and analytical chemistry, nanocomposites and interfaces has resulted in the first fundamental paper on grinding aids for cement (M. Weibel, R. K. Mishra, 'Comprehensive understanding of grinding aids' ZKG International 2014).
${ }^{\star}$ Correspondence: Dr. R. K. Mishra ${ }^{a}$

E-mail: rkmishra@ethz.ch

aDepartment of Civil, Environmental and Geomatic Engineering

ETH Zurich, $\mathrm{CH}-8093$ Zurich

bSika Technology AG

Tüffenwies 16, CH-8048 Zurich

'Sika Deutschland $\mathrm{GmbH}$

Peter-Schuhmacherstr. 8, D-69181 Leimen

dDepartment of Chemical and Biological Engineering

University of Colorado Boulder, Boulder, CO 80309-

0596, USA

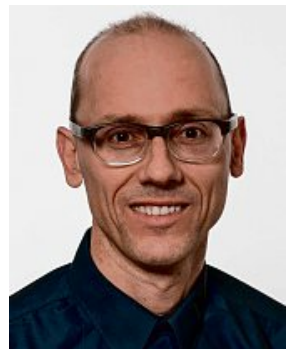

Martin Weibel made his PhD at the ETH Zurich, Institute of Polymers in the group of Prof. Ulrich Suter under the supervision of Dr. Walter Caseri (Synthesis and characterization of polymeric nanomaterials with high and ultrahigh refractive index

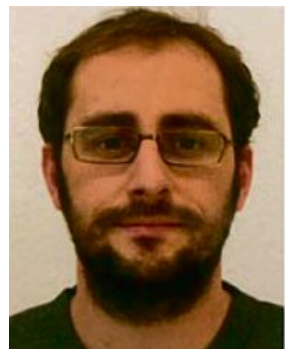

Thomas Müller finished his university degree (diploma) in Chemistryat FriedrichSchiller-University in Jena, Germany in 2003. After that he studied phytochemistry at the Universidad de Costa Rica in San Pedro, Costa Rica, investigating modifica- 
tions in metabolism of hyper accumulating plants after copper uptake. He returned to Friedrich-Schiller-University and obtained his PhD in 2008, working on synthesis and characterization of benzothiadiazol-containing polyarylene-vinylenes, conductive polymer dyes which are able to convert light into electricity. In 2008 he joined the $R \& D$ department at Sika Germany, leading the $R \& D$ group of cement additives, investigating fundamental working principles of grinding aids and quality improver, i.e. basic correlations between chemical structures of organic additives and impact on cement grinding, cement hydration by considering the composition of cement and phase composition of clinker. Since 2012 he is additionally responsible for the development of concrete admixtures, investigating correlation between structural elements of superplasticizer molecules and composition of cement as well as type, quantity and composition of supplementary cementitious materials and fillers.

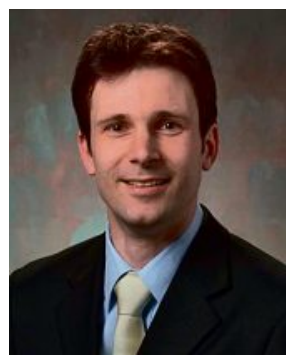

Hendrik Heinz is an Associate Professor at the University of ColoradoBoulder. He carried out postdoctoral work at the Air Force Research Laboratory in Dayton, Ohio, and received his PhD degree from ETH Zurich in 2003. His research focuses on molecular simulation of biological and nanostructured materials for medical, energy, and structural applications. He and his team integrated previously incompatible platforms for the simulation of biomolecules and for the simulation of inorganic compounds into one highly accurate platform for the simulation of functional materials across the periodic table. The new force fields and surface models enable the simulation of trillions of novel complex biointerfaces and hybrid inorganic-organic materials at the 1 to $1000 \mathrm{~nm}$ scale. Honors include election as a Fellow of the Royal Society of Chemistry (UK), the Max Hey Medal of the Mineralogical Society, an NSF Career Award, the Giovanni Novelli Prize of the Italian Clay Group, a Hewlett-Packard Outstanding Junior Faculty Award from the American Chemical Society, as well as invited guest professorships at ETH Zurich and at the National Institute for Materials Science (NIMS) in Tsukuba, Japan.

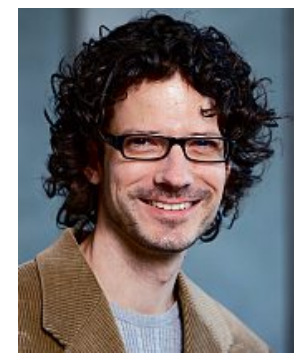

Robert J. Flatt is Professor for Physical Chemistry of Building Materials at ETH Zürich since 2010. Before that he was Principal Scientist at Sika Technology AG for 8.5 years and postdoctoral researcher at the Princeton University for 2.5 years. He owns a master in Chemical Engineering and a PhD from EPFL (Switzerland). His main research topic is the working mechanisms of chemical admixtures, which can be considered as the 'spices' of concrete. On this front he is laying the scientific basic for the molecular design of chemical admixtures to achieve targeted improvements of macroscopic properties, in particular for reducing the environmental footprint of concrete. An additional area of active research involving admixtures is digital fabrication with concrete, which is developed within the Swiss National Competence Centre on Digital Fabrication in Architecture. Recently, Robert co-edited the book 'Science and Technology of Concrete Admixtures' with Prof. Pierre-Claude Aüticn. He has also received several awards including the RILEM Medal as well as the Ross Coffin Purdy and the Stephen Brunauer awards from the American Ceramic Society.

\section{Introduction}

The comminution of inorganic solids (rocks, ores and clinker, etc.) consumes a significant amount of electrical energy. It has been reported that nearly $2-3 \%$ of all electrical energy generated on the planet was consumed by crushing and grinding. ${ }^{[1]}$ Inorganic materials in cement clinker are very finely comminuted to achieve a desired cement particle size distribution (PSD) before it can be used for construction purposes. ${ }^{[2]}$ In the case of cement production, this has major worldwide environmental implications because of the tremendous amounts of cement produced and $30 \%$ of the associated electrical energy consumption is used for grinding. ${ }^{[3]}$ In order to optimize this process, we focus on improving the energy efficiency by understanding the physical and chemical aspects of the grinding process.

For the grinding of inorganic solids in the presence of organic additives (grinding aids), some of the main benefits are: (a) reduction of energy consumption in the milling process, (b) increase in grinding efficiency, and (c) minimize the environmental impact. To give a scale of the environmental impact of cement production and the gains that can be made by reducing it, we point out that about $30-40 \%$ of the $\mathrm{CO}_{2}$ reductions targeted by Switzerland in the Kyoto protocol have been achieved by the cement industry alone. ${ }^{[4]}$ Innovation of efficient and economical chemical grinding aids requires a good understanding of mineral particle comminution in milling processes as well as molecular level interactions of organic additives with the clinker surface. Previously energy effective grinding of inorganic materials in the presence of organic additives were reported without detailed explanations on the proper working mechanisms at the molecular scale. ${ }^{[5]}$ In other words, most of the explanations were based on unverified assumptions.

Grinding aids have been used resourcefully for decades in the production of many materials, such as cements, ceramics, pigments, etc. Progression of the world cement production and rising grinding aids consumption are shown in Fig. 1a. The comminution process itself uses roughly two thirds of the associated electrical energy in cement production (Fig. 1b). Grinding aids help to reduce that energy demand during the size reduction significantly and this has a large-scale impact due to the volume of cement produced. The most commonly used materials in the grinding of cement clinker are triethanol amine, triisopropanolamine, glycerine, diethylene glycol, and propylene glycol.[5,6] The main aim of our research work was to foster innovation in this field and bring products with enhanced technological value to the market. For this, we investigated the working mechanisms of established grinding aids at the molecular level. ${ }^{[2,6,7]}$ In doing so, we progressively invalidated many widespread concepts about how these products work. From an industrial chemistry point of view, this led us to fundamentally rethink the molecular interactions that are needed to obtain a well-performing grinding aid. It also provided crucial insights into the more complex behavior of formulated products,,$[6,7 \mathrm{c}, 8]$ defining different roles that various compounds may play as well as their possible synergies. In this article, we review our research work on the working mechanisms of grinding aids used for clinker grinding at the atomistic scale. Here we do not focus on the meso-scale simulations which include the questions related to fragmentation of clinker particles, and simulation of industrial ball mills based on discrete element method that have been reported elsewhere. ${ }^{[2]}$ 

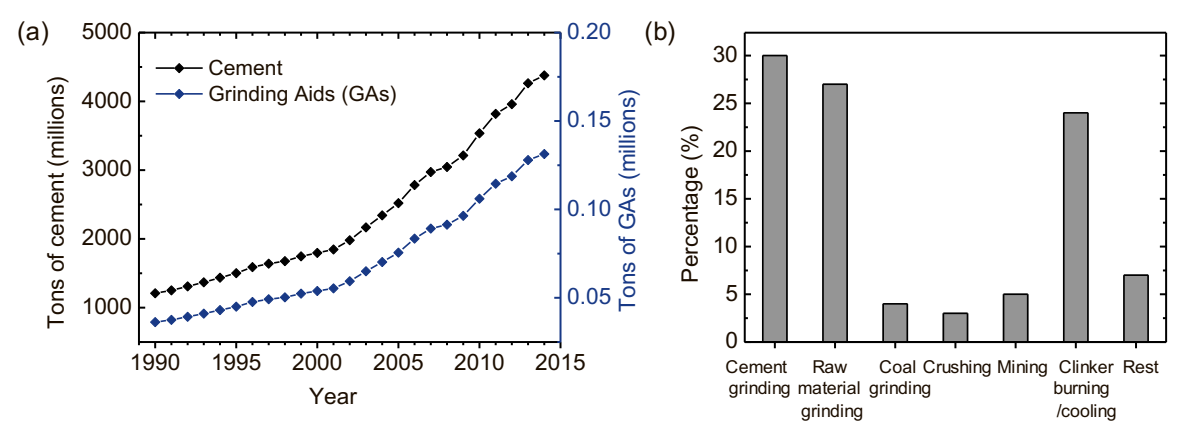

Fig. 1. Grinding aids and cement production. (a) Evolution of the world cement production and grinding aid consumption, (Source: CemNet Global Cement Report 11 $11^{\text {th }}$ Edition). ${ }^{[9]}$ (b) Fraction of electrical energy used in grinding. ${ }^{[3]}$

\section{Cement Production}

Cement is the binding phase in concrete, which is the most widely used material in the world (after water). It is therefore impossible to think about its substitution with any other materials such as steel, wood or brick, etc. ${ }^{[10]}$ Since extensive substitution is not an option, it is essential to reduce the environmental impact of concrete, most of which comes from cement production and accounts alone for $6-8 \%$ of man-made $\mathrm{CO}_{2}$ emissions. ${ }^{[11]}$ It is therefore of highest importance to reduce the deleterious environmental effect of cement production and this is where grinding aids can make a major contribution.

\subsection{Grinding of Cement Clinkers}

Cement clinker is composed of four main phases $\left(\mathrm{C}_{3} \mathrm{~S}, \mathrm{C}_{2} \mathrm{~S}, \mathrm{C}_{3} \mathrm{~A}\right.$ and $\mathrm{C}_{4} \mathrm{AF}$ where $\mathrm{C}$ : $\mathrm{CaO}, \mathrm{S}: \mathrm{SiO}_{2}, \mathrm{~A}: \mathrm{Al}_{2} \mathrm{O}_{3}$ and $\mathrm{F}$ : $\mathrm{Fe}_{2} \mathrm{O}_{3}$ ) that are produced by chemical reactions of a mixture mainly composed of calcined limestone and clay in a kiln at high temperature (Fig. 2.). ${ }^{[12]}$ Cement itself is the result of grinding clinker with small additions of calcium sulfate $(\sim 5 \%)$ as well as so-called supplementary cementitious materials (SCMs) such as limestone, slag, fly-ash, etc. It is in this last step of the operation that grinding aids are used. However, of even higher importance is the possibility of economically grinding cement clinker finer, as this means that other, less reactive materials (SCMs) with a lower environmental footprint, can be blended into the final cement without loss of initial reactivity. Grinding aids can therefore also be viewed as compounds that enable the production of blended cements of equal performance but reduced environmental impact. Additionally, grinding aids may also be designed to provide additional benefits, such as powder fluidity, improved fluidity of concrete, segregation resistance, carbon bleeding (staining) of fly ash, strength enhancement, etc. ${ }^{[13]}$

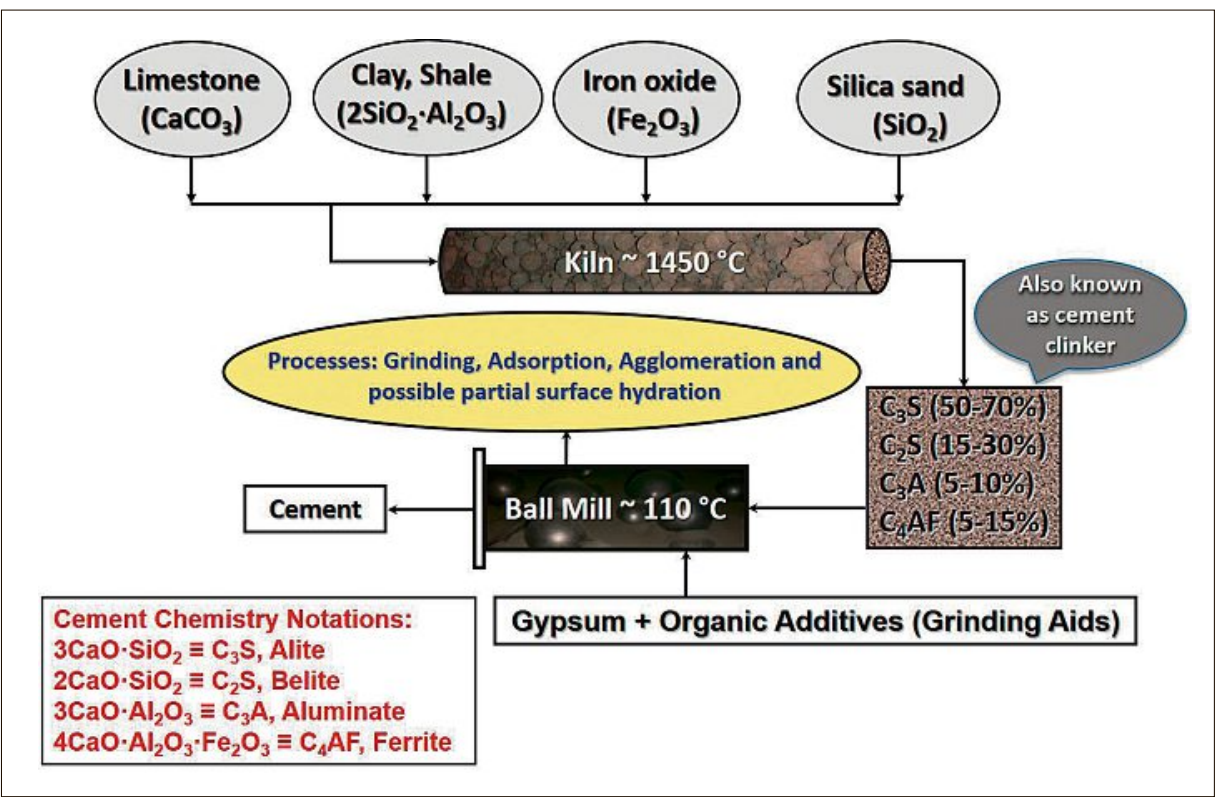

Fig. 2. Flowchart of cement production unit and various processes involved in a ball mill during particle size reduction. The main raw materials are limestone and clay. Other materials being used in smaller amounts to adjust the composition.

\subsection{Milling and Separation Process}

A very important aspect of comminution is that the milling station, generally a ball mill, is coupled with a separator, of which the task is to send coarse particles from the exit feed back into the mill (Fig. 3). Grinding aids can reduce the amount of agglomerates of ground particles, thereby enhancing the effectiveness of the separator. In other words, material that has been ground fine enough is not sent back into the mill. This represents a fundamental working mechanism of grinding aids of which we have studied the origin at a molecular level.

The milling process usually occurs at higher temperature $\left(90-120{ }^{\circ} \mathrm{C}\right)$ due to mechanical impact. Temperature rise in a ball mill leads to possible dehydration of mineral additives (e.g. gypsum) in cement which causes instant reaction of clinker phases $\left(\mathrm{C}_{3} \mathrm{~S}, \mathrm{C}_{2} \mathrm{~S}, \mathrm{C}_{3} \mathrm{~A}\right.$ and $\left.\mathrm{C}_{4} \mathrm{AF}\right)$ with water. We have discussed in detail partially hydrated surfaces of clinker phases in our previous papers. ${ }^{[7 a, b]}$ The temperature in the separator $\left(\sim 90^{\circ} \mathrm{C}\right)$ is slightly lower than the mill temperature because of inflow of air (Fig. 3c). Adsorption of grinding aids on the clinker surface depends on the temperature, which is therefore an important factor for a given system even if it does not have a major impact on comminution itself. We use both experimental tests and computer simulations to understand the physical and chemical mechanisms of action of grinding aids (discussed in sections 3 and 4 respectively).

\section{Experimental Results with Traditional and PCE-based Grinding Aids}

Since the 1930s, cement admixtures have been used in the grinding of cement. Even if the requirements for these cement additives have changed - additives are being used to optimize cement hydration and workability - an effective improvement in particle size reduction is still the prerequisite for the use of cement additives for cement grinding. ${ }^{[14]}$ Effective grinding aids are surface-active substances whose effect is based on the reduction of the occurring surface forces. This is manifested in particular by a reduction in agglomerate formation, a better dispersion in the separator and the avoidance of caking in the mill.

Chemical additives optimized for the grinding process in cement industry include alkanolamines, ${ }^{[15]}$ alcohols, ${ }^{[16]}$ polycarboxylate ether (PCE), ${ }^{[6]}$ and others. The increase in the mill throughput which can be achieved by the use of grinding aids usually moves in the range of $10 \%$ and $30 \%$, but can be up to $50 \%$ depending on the grinding system. The most common, 
(a)

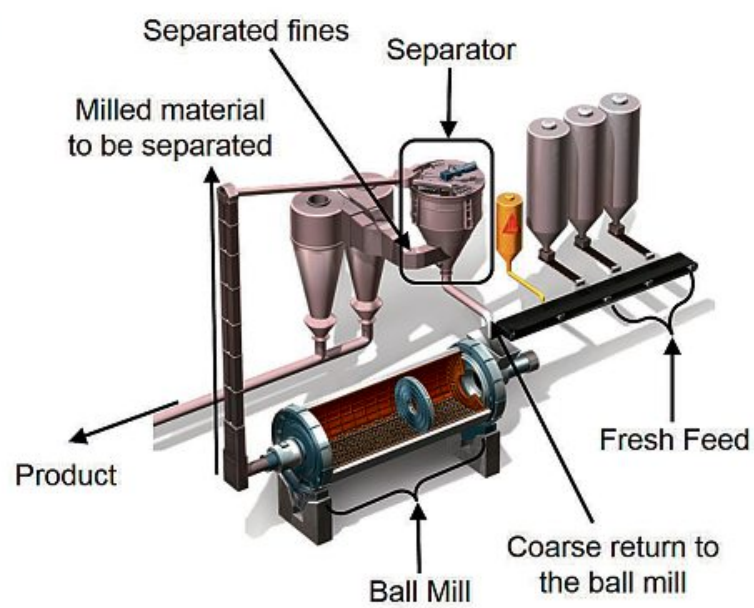

(b)

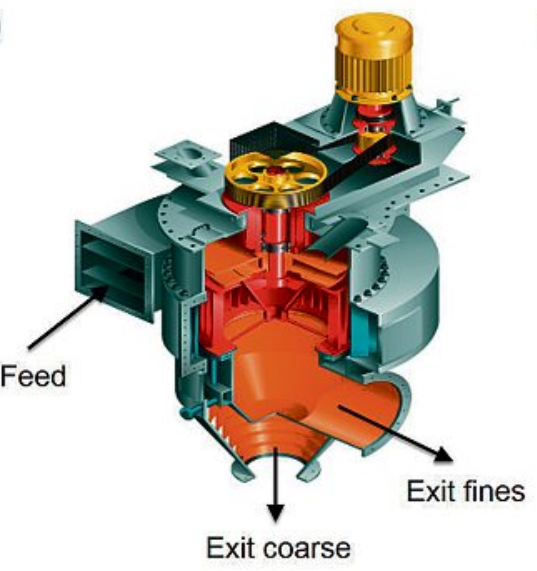

(c)

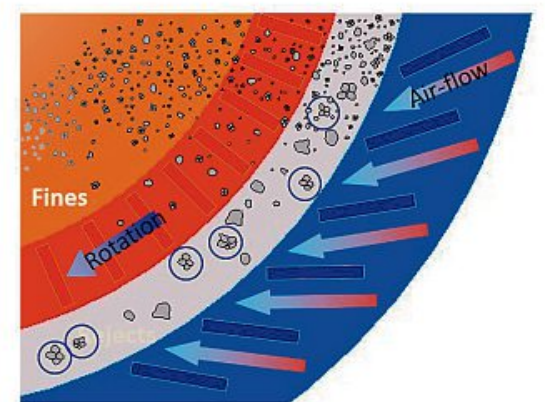

Fig. 3. Schematic representation of (a) milling station including an air separator; (b) Separator itself with main material flows indicated; (c) Insight on the main part of the separator showing how fine particles get blown through into the central part of the inner rotating part. ${ }^{[6]}$

so-called traditional cement additives are diethylene glycol (DEG), triethanol amine (TEA), triisopropanol amine (TIPA).

Heller et al. ${ }^{[6]}$ investigated the effect of polycarboxylate ethers ${ }^{[17]}$ on cement grinding, especially in combination with traditional grinding additives, on the basis of various laboratory and industrial scale trials. Within the framework of these investigations the cement grinding operations were carried out in a laboratory ball mill. The most important difference to

Fig. 4. Specific surface area according to Blaine fineness measurement in relation to additive dosage at constant grinding time. an industrial mill system is the absence of an air separator. In this case the grinding aid effect is also understood to come from dispersing particles, which prevents ground material from sticking to the milling media, thus keeping a higher grinding efficiency.

Grinding trials in the laboratory were carried out in batch operation. The aqueous additives were added in various dosages and the samples were milled for 60 minutes each. At a constant grinding time,

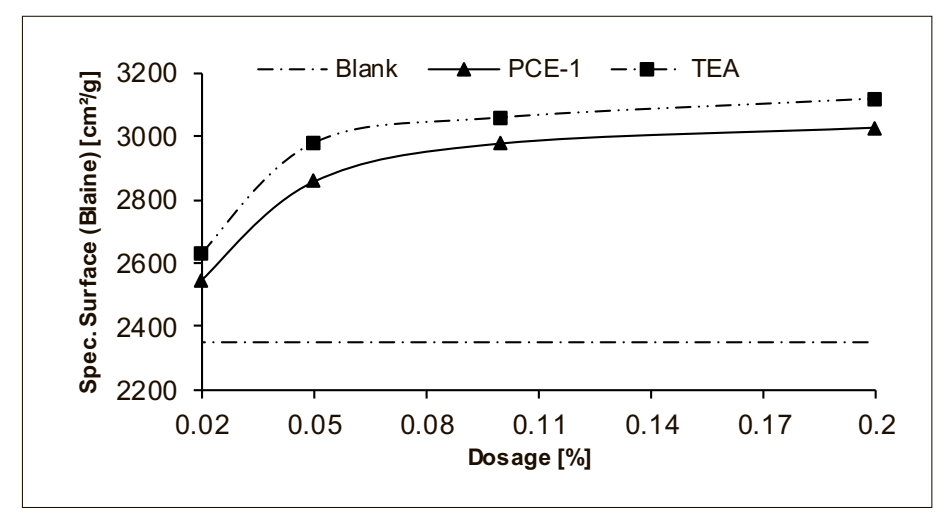

the effectiveness of the grinding additives was determined on the basis of the fineness obtained (specific surface according to Blaine). They found that PCE significantly increases the grinding efficiency, but not as much as TEA (Fig. 4).

In a further series of experiments, the efficacy of various mixtures of TEA and PCE was investigated (Fig. 5). As in the previous experiments, the fineness achieved with 'pure' PCE solution is lower than with the TEA solution. In blends, the fineness raises with increasing TEA content up to a mixing ratio of $1: 1$. If the TEA fraction is further increased, the fineness remains constant within the range of fluctuation. However, a constant increase in the series PCE, 10: 1 (PCE/TEA), ..., 1:10 (PCE/TEA), TEA was expected. The PCE-1 has a molar weight (Mw) of 46,000 $\mathrm{g} / \mathrm{mol}$. The ratio $\mathrm{C} / \mathrm{E}$ (free carboxylic/esterified) is 1.8 and side chains are made of methyl-polyethylene glycol.

Subsequent to the laboratory tests trials under real conditions in cement plants were carried out. For this purpose, different types of cement were ground on two-chamber ball mills with a dynamic air separator. In contrast to the laboratory batches, the efficacy of the grinding additives was determined by means of the production output at constant fineness. The example in Table 1 shows the results of the grinding of a cement type (CEM I $42.5 \mathrm{R}$ ). Initially, the cement was ground without additive, in the second part a TEA solution was used as a grinding aid. In the final phase, a formulation of two parts TEA and a portion of PCE was used as a grinding additive. The total active substance content of the formulation was $40 \%$ in each case. With the TEA solution the production output could be increased by $18 \%$. The PCE/TEA blend, on the other hand, was able to increase the production output by $22 \%$ compared to the reference. The additional production increase with the PCE/TEA blend, which was not to be expected due to the laboratory tests, can be explained by the dispersing effect of the PCE in the air separator. These studies demonstrate a decent transferability of the main results from the laboratory grinding tests to the industrial scale, but also underline that significant further gains can be made at the industrial scale that are not necessarily identifiable in batch tests carried out in a laboratory without an air separator.

In Table 2, we have presented the results of the grinding experiments using industrial grinding aids (MDIPA, TIPA, TEA, and glycerine). MDIPA is the most effective grinding aid, but it is difficult to understand the molecular scale mechanisms to know the reason behind the best performance except just noting these dif- 
Fig. 5. Specific surface area (Blaine) of samples ground with formulations of PCE-1 and TEA in different mixing ratios at constant grinding time; active ingredient of additives was $40 \%$, dosage $0.05 \%$; Reference: without additive.

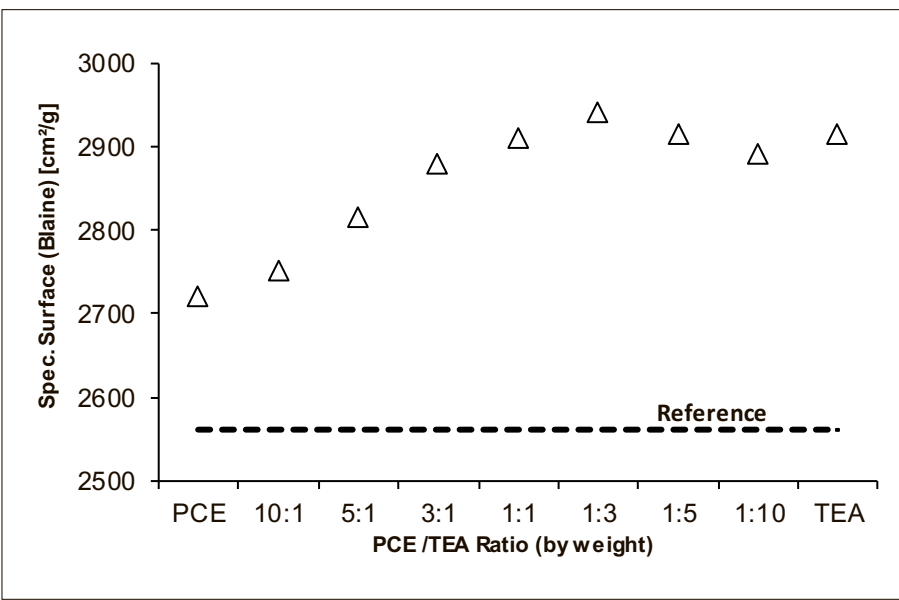

Table 1. Results of cement production plant for a cement type (CEM I 42.5 R) with and without organic additive.

$\begin{array}{lccc}\text { Parameters } & \begin{array}{c}\text { Reference } \\ \text { (without } \\ \text { additive) }\end{array} & \begin{array}{c}\text { TEA } \\ \text { (40\% active } \\ \text { content) }\end{array} & \begin{array}{c}\text { PCE-1/TEA (1:2) } \\ \text { (40\% active } \\ \text { content) }\end{array} \\ \text { Dosage grinding additive }[\mathrm{g} / \mathrm{t}] & - & 300 & 300 \\ \text { Blaine-value }\left[\mathrm{cm}^{2} / \mathrm{g}\right] & 3520 & 3580 & 3560 \\ \text { Production rate }[\mathrm{t} / \mathrm{h}] & 95 & 112 & 116\end{array}$

Table 2. Results of a laboratory mill used for grinding experiments to determine the normalized Blaine fineness and sieve residue at $32 \mu \mathrm{m}$ with respect to MDIPA grinding aid (GA). ${ }^{\left[{ }^{[2]}\right.}$

$\begin{array}{lcccc}\text { Compound } & \begin{array}{c}\text { Dosage of } \\ \text { GA, g per ton } \\ \text { of cement }\end{array} & \begin{array}{c}\text { Concentration } \\ \text { of GA in } \\ \text { water/wt-\% }\end{array} & \begin{array}{c}\text { Relative } \\ \text { Blaine } \\ \text { fineness/wt- } \%\end{array} & \begin{array}{c}\text { Relative sieve } \\ \text { residue at } \\ 32 \mu \mathrm{m} / \mathrm{wt} \text { - } \%\end{array} \\ \text { MDIPA } & 500 & 40 & 100 & 100 \\ \text { TIPA } & 500 & 40 & 95.8 & 107.8 \\ \text { TEA } & 500 & 40 & 92.7 & 112.1 \\ \text { Glycerine } & 500 & 40 & 90.5 & 118.5\end{array}$

ferences on fineness of particle and particle size distribution. Direct measurement of molecular scale mechanisms specially at the inorganic-organic interface is not possible during grinding. Also, to understand the correlation between experimental findings and the structure of the organic compound, atomistic scale simulations have been applied to understand the molecular interactions at the inorganic-organic interfaces and the effectiveness of grinding aids.

\section{Atomistic Simulations of Inorganic-Organic Interfaces}

From a molecular point of view, it is clear that in one way or another grinding aids operate by modifying surface prop-

\subsection{Necessity of Atomistic Model Validations}

The first challenge from a molecular perspective consisted in developing a reliable atomistic force field that would handle both the inorganic phases and the organic additives reliably at the 1 to $1000 \mathrm{~nm}$ scale. More specifically, this force field must properly describe surface and interfacial properties, something that is considered to be particularly challenging. [18] We thus oriented our efforts towards an approach that maximizes the amount of 'true chemical input' and devoted a lot of time to validating the force field in terms of bulk and surface properties of hydrated and unhydrated cement phases. ${ }^{[7 a, b, 18]}$ This has been achieved by reproducing the lattice constants of unit/super cells of crystal structures of inorganic minerals, mechanical properties (Young's and bulk modulus), vibrational properties (IR/Raman spectra), surface and interfacial energies in comparison to available experimental data.

\subsection{Modeling of Realistic Mineral Surfaces}

During the industrial grinding of clinker particles, dehydration of gypsum at ball mill temperature, moist raw materials, and also the occasional injection of cooling water leads to instant reactions of mineral surfaces with water and results in different degrees of surface hydration. For the clinker grinding process, we have considered to model only the first step of partial dissolution of $\mathrm{C}_{3} \mathrm{~S}$ which includes the water molecule reaction with top surface layer oxide ions to form hydroxide ions (Fig. 6). ${ }^{[7 b]}$ Similarly in the case of tricalcium aluminate, initial contact with water leads to the protonation of the first layer of aluminate rings and of the top portion of the second layer. The initial hydration reaction causes the formation of an amorphous layer of portlandite on the aluminate surface. ${ }^{[7 a]}$ Force field parameters of the bulk system cannot be applied without modifications to surfaces. Changes in the force field parameters (e.g. partial atomic charge) are shown in Scheme 1. Further hydration steps are beyond the scope of this work and extension has been described in our recent work on the hydration of tricalcium silicate. ${ }^{[19]}$

\subsection{Adsorption of Polar Organic Additives on Ionic Clinker Surfaces}

With this validated modeling framework in hand, we studied the most suitable set of organic molecules which includes alkanolamines, glycerine, glycols, and cationic polyelectrolytes (polycarboxylate ethers, PCEs) compounds. The first aspect examined was their interaction with the inorganic mineral surfaces including molecular mechanisms and the binding strength. This choice of organic compounds also 
makes it possible to understand the effect of hydrophobicity/hydrophilicity. The chemical structures of the selected commercial grinding aids, triisopropanolamine (TIPA), triethanolamine (TEA), N-methyl-diisopropanolamine (MDIPA) and glycerine are shown in Fig. 7. Other low molecular weight organic compounds are shown in Fig. 8. High molecular weight compounds such as PEO and PCE oligomers are shown in Fig. 9. PEO containing 39 monomer units and polycarboxylate ether with an equivalent molecular weight are $1736.08 \mathrm{~g} / \mathrm{mol}$ and $1717.71 \mathrm{~g} / \mathrm{mol} \mathrm{re-}$ spectively. To make modeling feasible, the molecular weight of the simulated PCE is a magnitude smaller than typical commercial polymers. The structure of PCE is based on the notation of Gay and Raphaël's diagram. ${ }^{[20]}$

The main molecular interactions of functional groups of grinding aids with the hydroxylated $\mathrm{C}_{3} \mathrm{~S}$ surface are reported in Table 3. Adsorption of these organic compounds occurs on the hydroxylated clinker surface mostly due to complexation of superficial calcium ions, hydrogen bonds and multipolar interactions (Fig. 10). Adsorption energies of organic additives on the hydroxylated $\mathrm{C}_{3} \mathrm{~S}$ surface were computed in a range of -0.12 to $-0.40 \mathrm{kcal} / \mathrm{g}$ (Table 4). The adsorption energy per unit mass in addition to the value per mol is practical as organic additives are applied in grams per ton of cement. The adsorption energy of TEA, TIPA, MDIPA, and glycerine does not correlate with the volatility (boiling point) of these compounds. The boiling points of DPGDME, DPGMME, DPG, and DEG follow in ascending order (Table 4). For this series, the increase in adsorption energy follows that of the boiling point.

In terms of adsorption, the PEO oligomer with an equivalent molecular weight to the PCE has a lower adsorption energy due to weak polar interactions with the surface. However, for the PCE considered, the electrostatic contribution to the total adsorption energy is only about $25 \%$. Interestingly polycarboxylate comb-copolymers are very widely used as dispersants for fresh concrete. ${ }^{[22]}$ In that case, these molecules adsorb through electrostatic interactions of their anionic backbone and induce steric hindrance between particles through their non-adsorbing side chains, typically made of polyethylene glycol.[23] It is therefore tempting to propose that a similar mechanism takes place during grinding, thus explaining the fact that these polymers are also effective grinding aids.

Our molecular modeling results however show that once again the a priori expectations on this subject are completely misplaced. Indeed, the behavior of the side

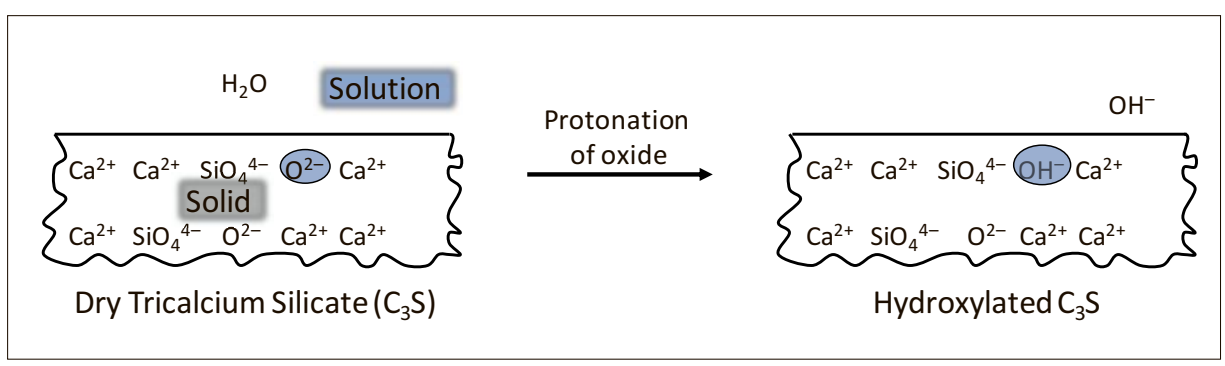

Fig. 6. The first step of hydration of $\mathrm{C}_{3} \mathrm{~S}$ which involves the chemical reaction between top surface layer oxide ions with a water molecule to form two hydroxide groups on the surface. ${ }^{[\mathrm{b}]}$

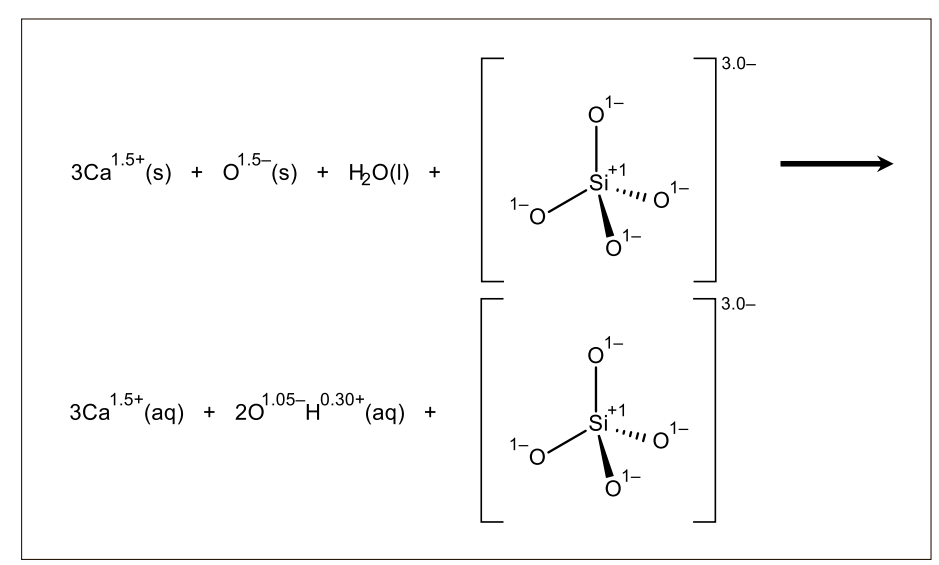

Scheme 1.

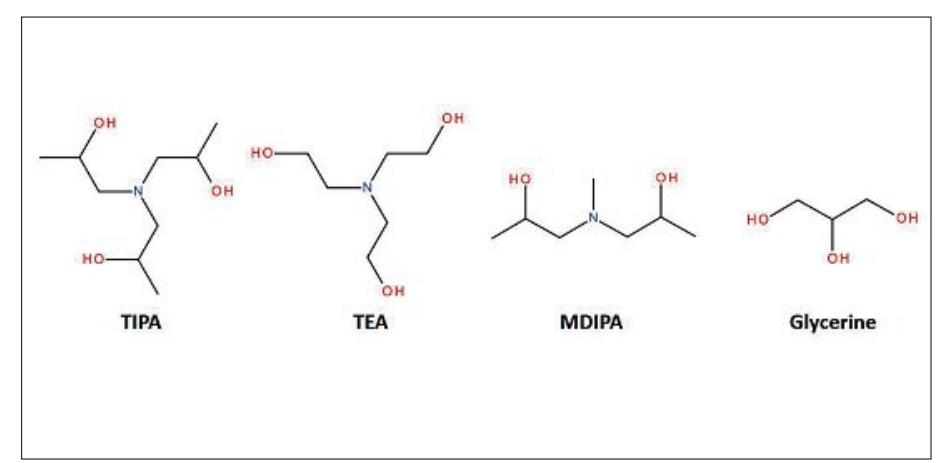

Fig. 7. Chemical structure of commonly used industrial grinding aids for cement such as triisopropanolamine (TIPA), triethanolamine (TEA), N-methyldiisopropanolamine (MDIPA), and glycerine. MDIPA has been added recently to this list. ${ }^{[21]}$

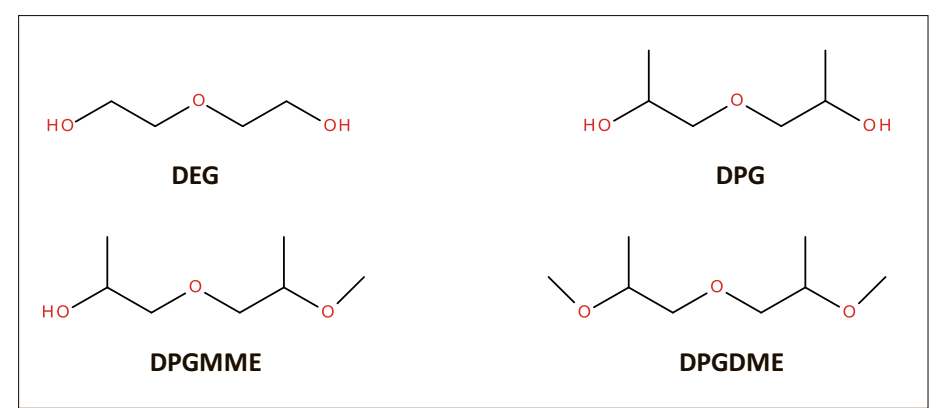

Fig. 8. Chemical structure of diethylene glycol (DEG), dipropylene glycol (DPG), dipropylene glycol monomethyl ether (DPGMME), and dipropylene glycol dimethyl ether (DPGDME).

(a)

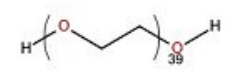

(b)

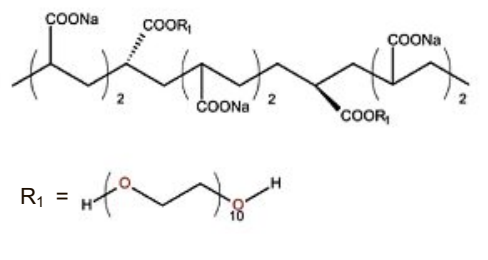

Fig. 9. Structure of (a) PEO (polyethylene oxide), and (b) PCE (polycarboxylate ether) molecules used for adsorption and agglomeration energy calculations using molecular dynamics simulations. 
Table 3. Main molecular interactions between polar functional groups of organic additives and hydroxylated (hyd.) tricalcium silicate surface at $110{ }^{\circ} \mathrm{C}$ grinding temperature.

\begin{tabular}{|c|c|c|c|c|c|}
\hline \multicolumn{2}{|c|}{ Functional group } & Surface binding sites & Surface & Interaction & Strength ${ }^{\mathrm{a}}$ \\
\hline Alcohol & RO-H & $\mathbf{O}-\mathrm{SiO}_{3}$ & Hyd. $\mathrm{C}_{3} \mathrm{~S}$ & $\mathrm{H} \cdots \mathrm{O}$ & Strong \\
\hline Alcohol & RO-H & O-H & Hyd. $\mathrm{C}_{3} \mathrm{~S}$ & $\mathrm{H} \cdots \mathrm{O}$ & Strong \\
\hline Alcohol & $\mathrm{RO}-\mathrm{H}$ & H-O & Hyd. $\mathrm{C}_{3} \mathrm{~S}$ & $\mathrm{O} \cdots \mathrm{H}$ & Weak \\
\hline Alcohol & $\mathrm{RO}-\mathrm{H}$ & $\mathrm{Ca}^{2+}$ & Hyd. $\mathrm{C}_{3} \mathrm{~S}$ & $\mathrm{O} \cdots \mathrm{Ca}^{2+}$ & Strong \\
\hline Amine & $\mathrm{R}_{3}-\mathbf{N}$ & $\mathrm{Ca}^{2+}$ & Hyd. $\mathrm{C}_{3} \mathrm{~S}$ & $\mathrm{~N} \cdots \mathrm{Ca}^{2+}$ & Absent \\
\hline $\begin{array}{l}\text { Carboxylate } \\
\text { Ether }\end{array}$ & $\begin{array}{l}\mathrm{R}-\mathrm{COO}^{-} \\
\mathrm{R}-\mathrm{O}-\mathrm{R}\end{array}$ & Present results show & $\begin{array}{l}\text { quivalent } \mathrm{r} \\
\text { PEO olig }\end{array}$ & $\begin{array}{l}\text { ular weight } \\
\text { on } \mathrm{C}_{3} \mathrm{~S} \text { surf }\end{array}$ & igher adsorption \\
\hline
\end{tabular}

${ }^{a}$ An approximate strength of $\mathrm{O} \cdots \cdot \mathrm{Ca}^{2+}$ coordination of $-8 \mathrm{kcal} / \mathrm{mol}$, and a $\mathrm{H} \cdots . \mathrm{O}$ hydrogen bond of $\sim-4 \mathrm{kcal} / \mathrm{mol}$ were estimated on the basis of adsorption data mentioned in Table 4.

Table 4. Adsorption energy of organic additives mentioned in Figs 7, 8, 9 on hydroxylated tricalcium silicate surface at grinding temperature $383 \mathrm{~K}$ $\left(110^{\circ} \mathrm{C}\right)$.

\begin{tabular}{|c|c|c|c|c|}
\hline System & $\begin{array}{c}\text { Adsorption } \\
\text { energy, kcal/g }\end{array}$ & $\begin{array}{l}\text { Main interaction } \\
\text { mechanisms }\end{array}$ & $\begin{array}{l}\text { Molecular weight of } \\
\text { organic compounds, } \\
\mathrm{g} / \mathrm{mol}\end{array}$ & $\begin{array}{l}\text { Boiling point } \\
\text { of organic } \\
\text { compounds, }{ }^{\circ} \mathrm{C}\end{array}$ \\
\hline TEA-Hyd. $\mathrm{C}_{3} \mathrm{~S}$ & $-0.12 \pm 0.02$ & \multirow{8}{*}{$\begin{array}{l}\mathrm{H} \cdots \mathrm{O}, \mathrm{O} \cdots \mathrm{Ca}^{2+} \text {, } \\
\text { and multipolar } \\
\text { interactions }\end{array}$} & 149.19 & 335 \\
\hline TIPA-Hyd. $\mathrm{C}_{3} \mathrm{~S}$ & $-0.13 \pm 0.01$ & & 191.27 & 306 \\
\hline MDIPA-Hyd. $\mathrm{C}_{3} \mathrm{~S}$ & $-0.19 \pm 0.01$ & & 147.22 & 248 \\
\hline Glycerol-Hyd. $\mathrm{C}_{3} \mathrm{~S}$ & $-0.40 \pm 0.03$ & & 92.09 & 290 \\
\hline DEG-Hyd. $\mathrm{C}_{3} \mathrm{~S}$ & $-0.38 \pm 0.02$ & & 106.12 & 245 \\
\hline DPG-Hyd. $\mathrm{C}_{3} \mathrm{~S}$ & $-0.27 \pm 0.03$ & & 134.17 & 230 \\
\hline DPGMME-Hyd. $\mathrm{C}_{3} \mathrm{~S}$ & $-0.20 \pm 0.02$ & & 148.20 & 190 \\
\hline DPGDME-Hyd. $\mathrm{C}_{3} \mathrm{~S}$ & $-0.15 \pm 0.02^{\mathrm{a}}$ & & 162.23 & 175 \\
\hline PEO-Hyd. $\mathrm{C}_{3} \mathrm{~S}$ & $-0.18 \pm 0.04$ & \multirow{2}{*}{$\begin{array}{l}\text { Polar and } \\
\text { electrostatic } \\
\text { interactions }\end{array}$} & 1736.08 & NA \\
\hline PCE-Hyd. $\mathrm{C}_{3} \mathrm{~S}$ & $-0.24 \pm 0.04$ & & 1717.71 & NA \\
\hline
\end{tabular}

aThere is no formation of hydrogen bond in the case of the DPGDME molecule.

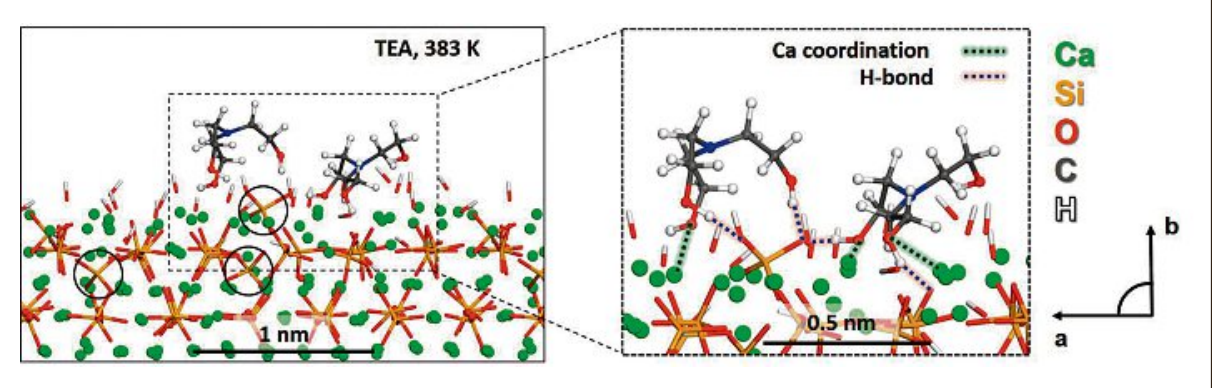

Fig. 10. Two TEA (triethanolamine) molecules on the hydroxylated tricalcium silicate surface, showing adsorption by hydrogen bonds and coordination of superficial $\mathrm{Ca}$ ions by hydroxyl groups (see inset). Circular highlights indicate surface reconstruction. ${ }^{[7]}$

chains is radically different between concrete mixing, where water is present, and cement grinding that takes place largely in absence of water (but enough for the surfaces to be partially hydroxylated). These very different conditions led the side chains to be non-adsorbing in fresh concrete and adsorbing on dry cement (Fig. 11). In particular, the adsorbed conformation is largely inverted between both situations. In ab- solute terms, their adsorption energies can be compared with commonly used grinding aids such as TEA, TIPA, MDIPA, and glycerine in terms of mass basis. The adsorption energy of PCE and PEO is found somewhere between MDIPA and glycerine (Table 4). Adsorption mechanisms of these organic molecules through experiment are difficult to access and molecular modeling can provide a welcome insight. In addition, as adsorption is a necessary condition for a grinding aid, it makes sense to compute this property. The grinding performance evaluated on the basis of Blaine values and sieve residues $(32 \mu \mathrm{m})$ gives the poorest and best result respectively for glycerine and MDIPA (Table 2). This implies that there is no correlation between adsorption energy and grinding performance. 


\subsection{Reduction of the Agglomeration Energy in the Presence of Organic Additives}

The agglomeration energy can be explained through the cleavage process happening during clinker grinding in ball mills. After cleavage of ionic clinker particles, quickly relaxed surfaces tend to attract each other due to strong electrostatic interactions. This leads to the formation of particle agglomerates. In terms of the energy requirement for such processes, this can be defined from the release of stored energy when two relaxed cleaved surfaces

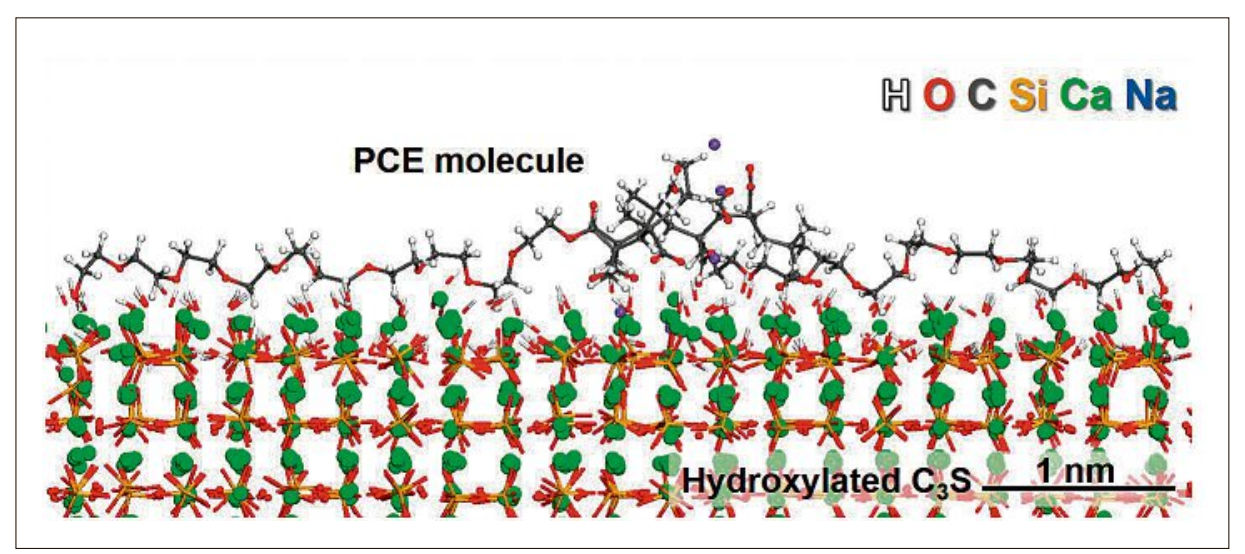

Fig. 11. Adsorption of a PCE molecule on the hydroxylated $\mathrm{C}_{3} \mathrm{~S}$ surface at $383 \mathrm{~K}$. Of particular interest is that the polyethylene glycol side chains adsorb, while the ionic backbone is further away from the surface. ${ }^{[24]}$ recombine or equally the required energy to separate them. ${ }^{[24]}$ We have computed such agglomeration energies of dry and hydroxylated clinker surfaces with and without grinding aids. Agglomeration energies of pure and hydroxylated clinker surfaces are clearly lower than their cleavage energies (Table 5). Indeed, hydroxylation leads to further decrease in agglomeration energy due to reduction of surface charges. Hydroxylated mineral surfaces are more realistic for the agglomeration energy calculations in the presence of grinding aids. Within the uncertainty from the compu-

tation, the agglomeration energy varies in a range of 3 to $10 \%$ upon temperature change from $25{ }^{\circ} \mathrm{C}$ to $90{ }^{\circ} \mathrm{C}$.

The reduction of agglomeration energy caused by industrial grinding aids (TEA, TIPA, MDIPA, and glycerine) has been discussed in detail for $\mathrm{C}_{3} \mathrm{~S}$ and $\mathrm{C}_{3} \mathrm{~A}$ minerals in our previous publications. ${ }^{[7]}$ Performance of grinding aids on both mineral surfaces were quite consistent except for TIPA. [7a] Tricalcium silicate surface has been considered in the rest of agglomeration energy calculations because it is the main phase of cement clinker. In this paper, we provide an overall picture of selected organic molecules tested for the agglomeration studies. To obtain efficient grinding aids, moderate adsorption of these organic molecules is needed on the mineral surface. Adsorption calculations help to select efficient organic molecules without providing the ranking of their performance. Reduction in agglomeration energy due to grinding aids are presented in Table 5 . MDIPA gives the best performance for reducing the surface forces between solid particles.

Adsorption and agglomeration energies (Tables 4 and 5) show examples of effects of hydrophobicity/hydrophilicity as well as of molecular size (Fig. 12). This can be explained by comparing dipropylene glycol, dipropylene glycol monomethyl ether and

Table 5. Computed cleavage energy and agglomeration energy ${ }^{a}$ of clinker phases using molecular dynamics simulations. ${ }^{[7 a, b, 19]}$ Agglomeration energies of the cleaved $\mathrm{C}_{3} \mathrm{~S}$ surfaces in the presence of grinding aids were computed at $90{ }^{\circ} \mathrm{C}$

Mineral

Tricalcium silicate $\left(\mathrm{C}_{3} \mathrm{~S}\right)$

Cleavage energy, $\mathrm{mJ} / \mathrm{m}^{2}$

Tricalcium aluminate $\left(\mathrm{C}_{3} \mathrm{~A}\right)$

$1300 \pm 50$

$1260 \pm 50$

Agglomeration energy, $\mathrm{mJ} / \mathrm{m}^{2}$

Tricalcium silicate $\left(\mathrm{C}_{3} \mathrm{~S}\right)$

Tricalcium aluminate $\left(\mathrm{C}_{3} \mathrm{~A}\right)$

$450 \pm 20$

$500 \pm 200^{\mathrm{a}}$

$240 \pm 12$

$250 \pm 50$

Agglomeration energy, $\mathrm{mJ} / \mathrm{m}^{2}$

$$
\begin{gathered}
52 \pm 8 \\
68 \pm 10 \\
97 \pm 10 \\
115 \pm 9 \\
92 \pm 8 \\
116 \pm 10 \\
175 \pm 15 \\
160 \pm 30
\end{gathered}
$$

Hyd. $\mathrm{C}_{3} \mathrm{~S}-\mathrm{PCE}$
Temperature, $\mathrm{K}$

$298\left(25^{\circ} \mathrm{C}\right)$

298

Separator temperature, $\mathrm{K}$

$363\left(90^{\circ} \mathrm{C}\right)$

363

363

Dosage of GA ( $\mathrm{g} /$ ton of cement)

aThe agglomeration energy depends on change in contact area between different cleaved surfaces due to surface displacements. This happens because of lateral shifts of the planes during the agglomeration process. ${ }^{\text {[7a] }}$ 
dipropylene glycol dimethyl ether. This choice makes it possible to understand the effect of hydrophobicity/hydrophilicity. We found that the replacement of hydroxyl functional groups by methyl groups changes the grinding efficiency. It explains the choice of functional groups shown in Table 3. Since DPGDME has no hydroxyl groups it cannot form hydrogen bonds with the $\mathrm{C}_{3} \mathrm{~S}$ surface. That is why DPGDME has the lowest adsorption energy. The adsorption energy of organic molecules depends on the number of hydrogen bonds as well as on polar interactions. The agglomeration energy in the presence of grinding aids correlates inversely with their grinding efficiency (Table 5). With this we concluded that balance of hydrophilicity/hydrophobicity groups is necessary for good performance.

From a molecular design point of view, this means that PCEs should be considered for their role of covering large surfaces at low dosages, in addition to the steric hindrance that may be evaluated in patches where the polymer is found to be locally at higher concentration. Sodium counter ions do not have a big role in this case due to nonspecific counter-ions binding to the backbone. Fig. 13 provides a molecular dynamics snapshot of the way in which these polymers conform between two surfaces of tricalcium silicate. Another interesting finding was that while PCEs act as effective dispersants in the areas where they are present, they occupy less surface, leaving more unoccupied patches. This means that in the low dosage ranges, typical for cement grinding, the amount of surface occupied is lower than with low molecular weight compounds. As a result, a part of their enhanced dispersion efficiency is lost because of this lower surface coverage. This can be remediated by using these polymers in combination with compounds of low molecular weight. It explains the fact that in practice, the best performance of PCEs is obtained, using them as a compound in formulated products (Fig. 5). More importantly, it provides conceptual rules about how such mixtures may be optimized considering the molecular structure of several compounds rather than a unique one. More systematic study of how such effects vary by changing the molecular architecture of PCEs may allow to develop similar 'molecular design tools' as were recently successfully established for the use of these polymers as dispersants in concrete. ${ }^{[25]}$

\section{Conclusions}

We have introduced a combined experimental and modeling approach for predicting the performance of grinding aids.

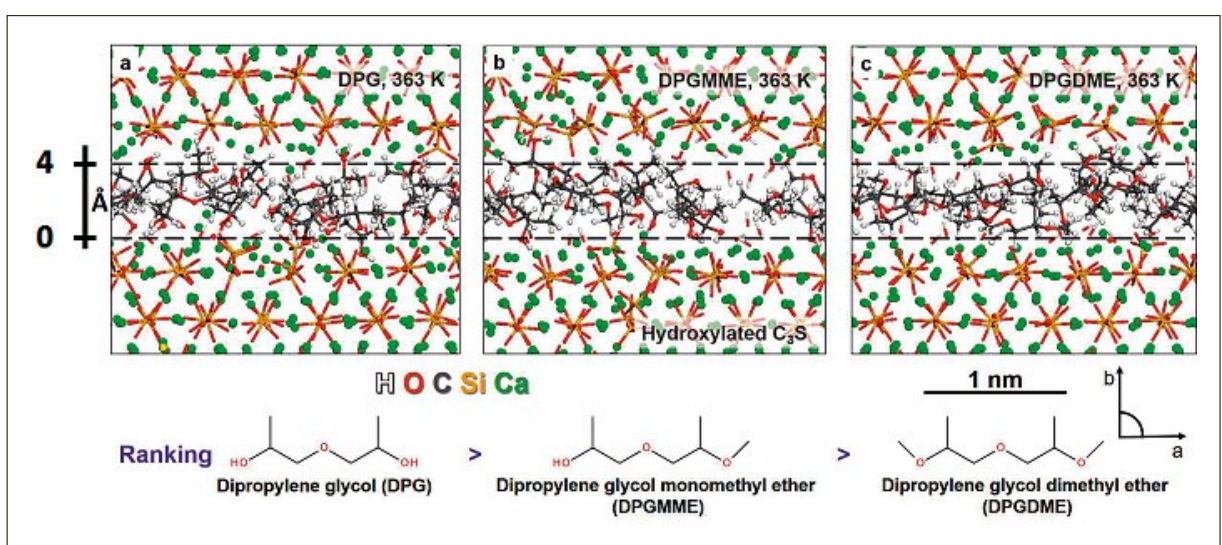

Fig. 12. Snapshot of (a) DPG, (b) DPGMME, and (c) DPGDME molecules confined between hydroxylated $\mathrm{C}_{3} \mathrm{~S}$ surfaces at temperature $363 \mathrm{~K}\left(90^{\circ} \mathrm{C}\right)$. Computed agglomeration energies correlate well with the results of grinding experiments.

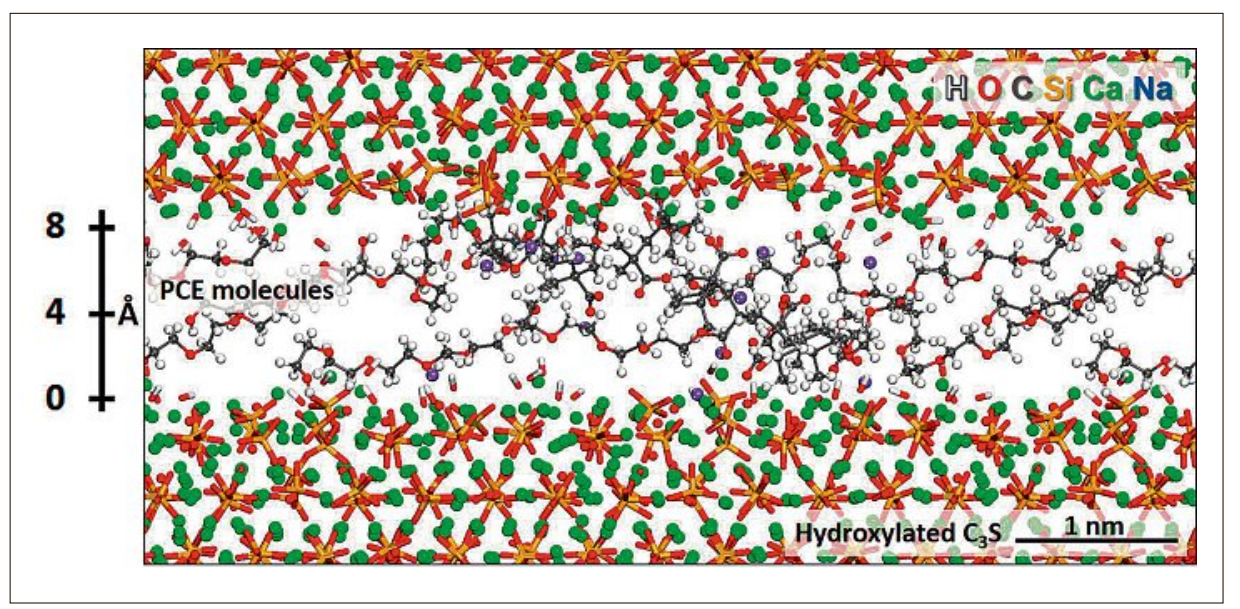

Fig. 13. Polycarboxylate ether (PCE) macromolecule between two hydroxylated surfaces of tricalcium silicate. The distance between the cleaved surfaces is $8 \AA$.

This approach helps in understanding the molecular interactions between inorganic mineral surfaces and organic additives. We performed the first molecular study of the factors controlling the performance of additives used to facilitate the grinding of inorganic solids, in particular cement. This requires the development and validation of the force field parameters for cement clinker phases that can be applied to the study of structural, interfacial, and mechanical properties of cement at the scale of 1 to $1000 \mathrm{~nm}$. A highlight of the outcome of this work has been to show that the ranking of the performance of traditional grinding aids based on average behavior in cement plants is well correlated with changes in agglomeration energies calculated by molecular modeling. Basically the agglomeration energy in the presence of grinding aids correlates inversely with the grinding performance. This success opens the doors to molecular insight into the factors controlling the performance of these additives and brings along a new way of considering the development as well as optimization of these compounds.

\section{Acknowledgements}

The authors acknowledge support by Sika Technology AG, the ETH Zurich Foundation, the University of Akron, the National Science Foundation (DMR 0955071), the Petroleum Research Fund of the American Chemical Society (grant no. 54135-ND10) and the Swiss Commission for Technological Innovation (KTI 13703.1 PFFLR-IW).

Received: June 26, 2017

[1] a) D. W. Fuerstenau, A. Z. M. Abouzeid, Int J. Mineral Proc. 2002, 67, 161; b) T. NapierMunn, Minerals Engin. 2015, 73, 1 .

[2] R. K. Mishra, D. Geissbuhler, H. A. Carmona F. K. Wittel, M. L. Sawley, M. Weibel, E. Gallucci, H. J. Herrmann, H. Heinz, R. J. Flatt, Adv. Appl. Ceramics 2015, 114, 393.

[3] M. Schneider, M. Romer, M. Tschudin, H Bolio, Cement and Concrete Res. 2011, 41, 642.

[4] R. Schürch, University of Bern, 2011

[5] a) H. El-Shall, P. Somasundaran, Powder Technol. 1984, 38, 275; b) S. Sohoni, R. Sridhar, G. Mandal, Powder Technol. 1991, 67, 277; c) A. A. Jeknavorian, E. F. Barry, F. Serafin, Cement and Concrete Res. 1998, 28, 1335.

[6] T. Heller, T. Muller, D. Honert, $Z K G$ International 2011, 40

[7] a) R. K. Mishra, L. Fernandez-Carrasco, R. J. Flatt, H. Heinz, Dalton Trans. 2014, 43, 10602; 
b) R. K. Mishra, R. J. Flatt, H. Heinz, J. Phys. Chem. C 2013, 117, 10417; c) R. K. Mishra, H. Heinz, J. Zimmermann, T. Müller, R. J. Flatt, ACI Special Publication 2012, 288, 1 .

[8] D. Honert, T. Heller, T. Müller, US20160024307 A1, 2014.

[9] 'Global Cement Report', 11th Edition ed., I. C. Review, 2015.

[10] R. J. Flatt, N. Roussel, C. R. Cheeseman, J. Eur. Ceramic Soc. 2012, 32, 2787

[11] E. Gartner, H. Hirao, Cement and Concrete Res. 2015, 78, 126.

[12] H. F. Taylor, 'Cement chemistry', Thomas Telford, 1997.

[13] a) E. Gartner, D. Myers, J. Am. Ceramic Soc. 1993, 76, 1521; b) V. S. Ramachandran, Cement and Concrete Res. 1976, 6, 623.
[14] L. Sottili, D. Padovani, ZKG International 2000, 53,568 .

[15] P. J. Sandberg, F. Doncaster, Cement and Concrete Res. 2004, 34, 973

[16] W. F. Li, S. H. Ma, X. D. Shen, in 'Trans. Tech. Publ.', Vol. 860, 2014, p. 1040.

[17] G. Gelardi, S. Mantellato, D. Marchon, M. Palacios, A. Eberhardt, R. Flatt, in 'Science and Technology of Concrete Admixtures', Woodhead Publishing: Sawston, UK, 2016, p. 149

[18] H. Heinz, T.-J. Lin, R. K. Mishra, F. S. Emami, Langmuir 2013, 29, 1754.

[19] E. Pustovgar, R. K. Mishra, M. Palacios, J. B D. E. De Lacaillerie, T. Matschei, A. Andreev, H. Heinz, R. Verel, R. J. Flatt, Cement and Concrete Res. 2017, doi.org/10.1016/j. cemconres.2017.06.006.
[20] C. Gay, E. Raphaël, Adv. Coll. Interf. Sci. 2001, 94, 229.

[21] B. Marazzani, C. Burge, C. Kurz, T. Müller, WO/2012/160210, 2012

[22] J. Plank, E. Sakai, C. W. Miao, C. Yu, J. X Hong, Cement and Concrete Res. 2015, 78, 81.

[23] G. Gelardi, R. Flatt, in 'Science and Technology of Concrete Admixtures', Woodhead Publishing: Sawston, UK, 2016, p. 257.

[24] M. Weibel, R. K. Mishra, ZKG International 2014, 67, 28.

[25] D. Marchon, P. Juilland, E. Gallucci, L. Frunz, R. J. Flatt, J. Am. Ceramic Soc. 2017, doi:10.1111/jace.14695. 